3. Монгуш, Л. Т. Подбор бобово-злаковых травосмесей для создания сеяных сенокосов в экстремальных условиях Республики Тыва / Л. Т. Монгуш. - Текст: непосредственный // Международный журнал прикладных и фундаментальных исследований. - 2017. - № 11-1. C. 112-117.

4. Модина, Т. Д. Климат и агроклиматические ресурсы Алтая / Т. Д. Модина, М.Г. Сухова. Новосибирск: Универсальное книжное издательство, 2007. - 180 с. - Текст: непосредственный.

5. Агрохимическая характеристика сельскохозяйственных угодий Республики Алтай (19722009 гг.): пособие / МСХ РФ ФГУ САС «ГорноАлтайская». - Горно-Алтайск: ОАО «ГорноАлтайская типография», 2010 - 63 с. - Текст: непосредственный.

6. Методика опытов на сенокосах и пастбищах / ВНИИК им. В. Р. Вильямса. - Москва: Агропромиздат. - 1971. - 232 с. - Текст: непосредственный.

\section{References}

1. Kashevarov N.I. Agrotekhnologii proizvodstva kormov v Sibiri / N.I. Kashevarov, V.P. Danilov, R.I. Poliudina i dr. - Novosibirsk, 2012. - 247 s.
2. Bents V.A. i dr. Polevoe kormoproizvodstvo v Sibiri / V.A. Bents, N.I. Kashevarov, G.A. Demarchuk. - Novosibirsk, 2001. - $240 \mathrm{~s}$.

3. Mongush L.T. Podbor bobovo-zlakovykh travosmesei dlia sozdaniia seianykh senokosov $\mathrm{v}$ ekstremalnykh usloviiakh Respubliki Tyva // Mezhdunarodnyi zhurnal prikladnykh i fundamentalnykh issledovanii. - 2017. - No. 11-1. S. 112-117.

4. Modina T.D., Sukhova M.G. Klimat i agroklimaticheskie resursy Altaia. - Novosibirsk: Universalnoe knizhnoe izdatelstvo, 2007. $180 \mathrm{~s}$.

5. Agrokhimicheskaia kharakteristika selskokhoziaistvennykh ugodii Respubliki Altai (19722009 gg.): posobie / MSKh RF FGU SAS «GornoAltaiskaia». - Gorno-Altaisk: OAO «GornoAltaiskaia tipografiia», $2010-63 \mathrm{~s}$.

6. Metodika opytov na senokosakh i pastbishchakh / VNIIK im. V.R. Viliamsa. - Moskva: Agropromizdat, 1971. - $232 \mathrm{~s}$.

Работа выполнена при частичной поддержке РФФИ и Республики Алтай по проекту № 20-44040002 р_а и в рамках Государственного задания Минобрнауки РФ по теме № $A A A A-A 19-$ 119092490021-6.

\title{
$\downarrow \downarrow$
}

УДК 635.9:631.529:631.527

DOI: 10.53083/1996-4277-2021-203-09-25-29
Н.В. Антропова

N.V. Antropova

\section{ПРОДОЛЖИТЕЛЬНОСТЬ И ПРОДУКТИВНОСТЬ ЦВЕТЕНИЯ ЭЛИТНЫХ ГИБРИДОВ ЛИЛЕЙНИКА HEMEROCALLIS L. В УСЛОВИЯХ ЛЕСОСТЕПИ АЛТАЙСКОГО КРАЯ}

\section{DURATION AND PRODUCTIVITY OF FLOWERING OF ELITE HYBRIDS OF DAYLILY HEMEROCALLIS L. IN THE CONDITIONS OF THE FOREST-STEPPE OF THE ALTAI TERRITORY}

Ключевые слова: Hemerocallis L., гибрид, потомство, цветок, окраска, диаметр, цветонос, донор, признак, декоративность.

Представлены результаты изучения гибридов лилейника (Hemerocallis L.). Цель работы - изучить гибриды лилейника с разнообразной окраской, продолжительным и продуктивным цветением, адаптированные к условиям лесостепи Алтайского края. Объекты исследования: контрольный сорт Golden Goft, 9 перспективных гибридов 2006-2008 гг. скрещивания лилейника алтайской селекции. Исследования проводили согласно общепринятой методике. В 2015, 2019, 2020 гг. зимних повреждений у гибридов лилейника не отмечено. Отрастание побегов наблюдалось 13.0420.04 , начало цветения - 10.06-2.08. Общая продолжительность декоративности гибридов более 2,5 месяцев (10.06-07.09). Генеративная продуктивность у изучаемых гибридов - 18-270 цветков на куст. Большинство гибридов красной окраски. Гибрид 20-07-17 имеет паукообразную форму цветка, 3-07-3 - звездообразную, а остальные - округлую и треугольную. Диаметр цветка у гибридов варьировал в пределах 7,4-16,2 см, у контрольного - 10,2 см. Кусты разрастались в ширину у гибридов от 37 до 62 см. Высота куста изменяется на уровне 40-64 см, что важно для создания ландшафтных композиций для озеленения городских и приусадебных участков. У всех изучаемых гибридов деко- 
ративные и продуктивные признаки отмечены высокие, среди них выделены претенденты в сорта и для дальнейшей селекции и расширения генетического разнообразия. В результате изучены обильно цветущие гибриды лилейника Hemerocallis L. c ранним, средним, поздним сроком цветения, позволяющие увеличить продолжительность декоративности более 2,5 мес. К лучшим отнесены гибриды 1-06-15 - высокорослый, красной окраски и треугольной формы цветка; 20-07-17 - высокорослый, крупноцветковый, красной окраски и паукообразной формы цветка; 4-07-150 - малиновокрасной окраски и треугольной формы цветка; 7-07-5 ярко-красной окраски и треугольной формы цветка; 19-08-2 - малиновой окраски и треугольной формы цветка.

Keywords: daylily (Hemerocallis L.), hybrid, progeny, flower, color, diameter, peduncle, donor, character, ornamental value.

The results of studying daylily hybrids (Hemerocallis $L$.) are discussed. The research goal is to study daylily hybrids with different colors, long and productive flowering, and adapted to the conditions of the Altai Region's foreststeppe. The research targets were as following: the control variety Golden Gift and 9 promising hybrids of 2006-2008 obtained by crossing of the daylily developed in the Altai Region. The studies were carried out according to the gen-

Антропова Наталья Викторовна, к.С.-Х.Н., Н.С., ФГБНУ «Федеральный Алтайский научный центр агробиотехнологий», г. Барнаул, Российская Федерация, e-mail: niilisavenko20@yandex.ru.

Селекцией лилейника гибридного Hemerocallis $L$. начали заниматься в Европе c XIX в., caмый первый сорт Articot создал George Yeld. Большой вклад внесли в расширение новых сортов L. Burbank (сорт Calipso), Arlow Stout (более 200 гибридов и сортов) [5]. Первые тетраплоидные гибриды были получены в 60-е годы XX в. в США [4]. В Беларусии в 2008 г. был зарегистрирован первый сорт Unexpected Joy, coзданный М. Спиридоновой [7]. В последние десятилетия появляются новые сорта с необычной формой лепестков, окраской, различной величиной цветка. Ассортимент лилейника расширяется с каждым годом и насчитывает около 70 тыс. сортов [6]. В Алтайском крае с лилейниками работали И.В. Верещагина, К.С. Попова (19652006 гг.). Получены путём свободного опыления сорта Улыбка Солнца и Клавдия. Из зарубежных сортов наиболее адаптированные к условиям лесостепи Алтайского края отнесены сорта с жёлтой окраской, как у природного вида. Не все сорта способны зимовать, обильно и продолжи- erally accepted methodology. In 2015, 2019, and 2020, no winter damage was observed in daylily hybrids. Shoot growth was observed from April 13 to April 20; the beginning of flowering - from June 10 to August 2. The total duration of the hybrids' ornamental value made over 2.5 months (from June 10 to September 7). The generative productivity in the studied hybrids was 18-270 flowers per plant. Most hybrids were red in color. The hybrid 20-07-17 had a spider-like flower shape; 3-07-3 - star-shaped; the rest had rounded and triangular flowers. Flower diameter in the hybrids varied within 7.4-16.2 cm; in the control $10.2 \mathrm{~cm}$. The hybrid plants grew in width to $37-62 \mathrm{~cm}$. The plant height varies from 40 to $64 \mathrm{~cm}$ which is important for creating flower arrangements for urban and household plot landscaping. All the studied hybrids have high ornamental and productive characteristics; among them there are candidate varieties for further selective breeding and expansion of genetic diversity. As a result, profusely blooming hybrids of daylily Hemerocallis $L$. with early, medium, and late flowering were studied; this would allow increasing the duration of ornamental value for more than 2.5 months. The best are the following hybrids: 1-06-15 - tall, redcolored and triangular-shaped flower; 20-07-17 - tall, largeflowered, red-colored and spider-shaped flower; 4-07-150 crimson-red color and triangular shape of the flower; 7-07-5 - bright red color and triangular shape of the flower; 19-08-2 - crimson color and triangular shape of the flower.

Antropova Natalya Viktorovna, Cand. Agr. Sci., Staff Scientist, Federal Altai Scientific Center of AgroBiotechnologies, Barnaul, Russian Federation, e-mail: nilisavenko20@yandex.ru.

тельно цвести в условиях Западной Сибири, поэтому актуально создавать наши сорта, пригодные для создания ландшафтных композиций в озеленении городских и приусадебных участков.

Цель работы - изучить гибриды лилейника с разнообразной окраской, продолжительным цветением в условиях лесостепи Алтайского края.

Задачи исследования:

1) выделить высокопродуктивные с продолжительным декоративным периодом элитные гибриды лилейника;

2) оценить хозяйственно-биологические и декоративные показатели гибридов лилейника.

\section{Объекты, методика}

\section{и условия проведения исследования}

Объекты исследования: контрольный сорт Golden Goft, 9 отборных форм лилейника из 310 сеянцев 2006-2008 гг. скрещивания. Зимостойкость, фенологическое и морфологическое описание гибридов проводилось в 2015, 2019, 
2020 гг. по 3-5 модельным растениям. Исследования осущствляли согласно общепринятым методикам $[1,3]$. Место проведения научной работы - ЭПО №1 ФГБНУ ФАНЦА. Посадки 2013 г. по схеме - 0,8×0,3 м. Ряды ориентированы в направлении с юго-востока на северо-запад. За сезон проводились две междурядные обработки и три ручные прополки. Почва опытного участка - чернозём выщелоченный, маломощный. Гумус содержится в слое 0-20 см - 7\%, подвижных форм фросфрата - 23,8-35,5 мг/100 г, азота - 0,090,62, калия - 5,0-10,4 мг/100 г [2].

В период роста и развития лилейника отмечены погодные условия как наиболее тёплые и слабо увлажнённые в 2015 и 2019 гг., а как жаркий и слабо увлажнённый - в 2020 г. Осадков за сезон в 2015 г. выпало 232 мм, в 2019 г. - 212, в 2020 г. - 233 мм. Сумма температур выше 100 в 2015 г. $-2529,0^{\circ} \mathrm{C}$, в 2019 г. $-2337,2^{\circ} \mathrm{C}$, в 2020 г. $-2671,1^{\circ} \mathrm{C}$. Погодные условия были благоприятны в период вегетации гибридов.

\section{Результаты исследования}

Из 310 гибридных сеянцев было отобрано 9 перспективных гибридов. В 2015, 2019, 2020 гг. зимних повреждений у гибридов лилейника не отмечено. Отрастание побегов наблюдалось с 13.04 по 20.04 (V=6,5\%). В 3-, 6-, 7-летнем возрасте все межсортовые гибриды цвели. Начало цветения по гибридам 10.06-02.08 (в среднем $14.07 \pm 4,9, \mathrm{~V}=10,3 \%$ ) (табл. 1).

Хозяйственно-биологическая характеристика гибридов лилейника

Таблица 1

\begin{tabular}{|c|c|c|c|c|c|c|}
\hline \multirow{2}{*}{$\begin{array}{c}\text { Гибрид, срок } \\
\text { цветения }\end{array}$} & \multicolumn{3}{|c|}{ Цветение } & \multicolumn{2}{|c|}{ Количество, шт. на куст } & $\begin{array}{c}\text { Суммарная } \\
\text { оценка, } \\
\text { балл }\end{array}$ \\
\hline $\begin{array}{c}\text { Контроль } \\
\text { Golden Goft, с. }\end{array}$ & $14.07 \pm 2,0$ & $18.08 \pm 5,0$ & $35 \pm 3,0$ & $2 \pm 0,3$ & $66 \pm 13,9$ & 32 \\
\hline $1-06-15$, p. & $10.06 \pm 4,2$ & $15.07 \pm 5,2$ & $36 \pm 3,5$ & $10 \pm 0,5$ & $270 \pm 31,0$ & 46 \\
\hline $3-07-3$, c.p. & $16.07 \pm 6,2$ & $6.08 \pm 5,0$ & $20 \pm 2,9$ & $5 \pm 1,9$ & $52 \pm 22,0$ & 33 \\
\hline $4-07-150$, с. & $14.07 \pm 0,6$ & $15.08 \pm 2,9$ & $35 \pm 1,2$ & $8 \pm 1,2$ & $151 \pm 12,5$ & 43 \\
\hline $7-07-5$, c. & $17.07 \pm 0,6$ & $15.08 \pm 1,7$ & $30 \pm 2,3$ & $6 \pm 2,4$ & $66 \pm 33,8$ & 39 \\
\hline $20-07-17$, с. & $15.07 \pm 1,2$ & $20.08 \pm 6,0$ & $37 \pm 7,2$ & $9 \pm 2,7$ & $195 \pm 39,7$ & 49 \\
\hline $22-07-4$, c. & $16.07 \pm 0,6$ & $13.08 \pm 6,9$ & $29 \pm 6,3$ & $4 \pm 2,9$ & $41 \pm 17,9$ & 30 \\
\hline $8-08-9$, с. & $20.07 \pm 2,3$ & $10.08 \pm 6,3$ & $22 \pm 4,0$ & $2 \pm 0,3$ & $18 \pm 5,3$ & 29 \\
\hline $19-08-2$, п. & $2.08 \pm 4,0$ & $7.09 \pm 1,2$ & $37 \pm 2,4$ & $6 \pm 2,7$ & $121 \pm 59,0$ & 47 \\
\hline $19-08-3$, c.p. & $15.07 \pm 1,2$ & $6.08 \pm 2,3$ & $23 \pm 2,7$ & $3 \pm 0,9$ & $55 \pm 21,8$ & 29 \\
\hline Min-Max & $10.06-2.08$ & $15.07-7.09$ & $20-37$ & $2-10$ & $18-270$ & $27-49$ \\
\hline$X \pm x$ & $14.07 \pm 4,9$ & $12.08 \pm 4,7$ & $30 \pm 2,3$ & $5,9 \pm 0,9$ & $108 \pm 27,9$ & \\
\hline V, \% & 10,3 & 8,6 & 22,7 & 45,8 & 77,6 & \\
\hline
\end{tabular}

Примечание. р. - ранний срок цветения; с.р. - среднеранний; с. - средний; п. - поздний.

Самое раннее цветение $(10.06 \pm 4,2)$ отмечено у гибрида 1-06-15, наиболее позднее - у гибрида 19-08-2 (02.08 $\pm 4,0)$. В сравнении с контролем 6 гибридов зацвели приблизительно в те же сроки (14-17.07), кроме гибридов 8-08-9 (20.07士2,3) и 19-08-2 (02.08 $\pm 4,0)$. Лилейники превосходят многие декоративные многолетники по длительности цветения (20-37 дней), так как на цветоносе образуется до 27 цветков. Самое короткое цветение установлено у гибрида 3-07-3 (20 $\pm 2,9$ дней), длительное - у гибридов 19-08-2

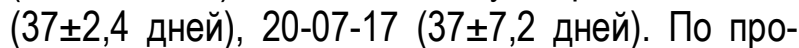
должительности цветения гибриды 3-07-3, 8-08-9, 19-08-3 (20-23 дня) существенно превосходят контрольный сорт Golden Goft (на
12-15 дней), а гибриды 1-06-15, 20-07-17, 19-08-2 (36-37 дней) незначительно (на 1-2 дня). Общая продолжительность декоративности всех гибридов от начала до конца цветения более 2,5 мес. (10.06 (ранний - 1-06-15) - 07.09 (поздний 19-08-2). Для удлинения периода цветения нами подобраны гибриды раннего - 1 , среднераннего - 2, среднего - 5, позднего - 1. Генеративная продуктивность у изучаемых гибридов отмечена 18-270 цветков на куст (в среднем 108 $\pm 27,9$ ). Максимальное количество цветков на куст у гибридов: 7-07-5 (66 $\pm 33,8), \quad 19-08-2 \quad(121 \pm 59,0)$,

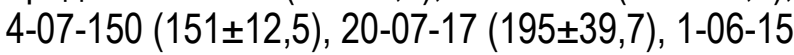
$(270 \pm 31,0)$. У гибридов 3-07-3 и 8-08-9 разное количество цветков, длительность цветения у 
них одинаковая. Так, у первого 3-07-3 цветки зацветали одновременно по несколько, а у гибрида 8-08-9 - последовательно. Балльная оценка по хозяйственно-биологическим показателям по гибридам составляла от 27-49, у контроля - 32. Максимальную оценку (выше 35 баллов) получили 5 гибридов.

По окраске околоцветника гибриды разделены на 6 групп: жёлтая - 1, розовая - 2, малиновая - 2, красная - 4 (табл. 2). Большинство гибридов красной и розовой окраски. Гибрид 20-07-17 имеет паукообразную форму цветка, 3-07-3 - звездообразную, а остальные округлую и треугольную. Диаметр цветка у гибридов варьировал от 7,4士0,1 (22-07-4 с лимонно-жёлтой окраской) до 16,2士0,2 см (20-07-17 с красной окраской), у контрольного - 10,2士0,1 см.

Ширина куста лилейника изменялась от $37 \pm 1,4$ см (у гибрида 8-08-9) до 62 $\pm 4,0$ см (у гибрида 19-08-3) (в среднем 52,2 22,9 см, $\mathrm{V}=16,5 \%)$. Все они уступают контрольному сорту

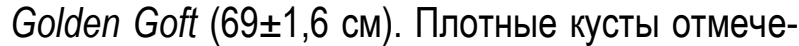
ны у гибридов 8-08-9, 3-07-3, 4-07-150, 22-07-4, рыхлые - 1-06-15, 19-08-2, 19-08-3. Листва у лилейника декоративна весь сезон, поэтому важно знать высоту листьев. Высота куста во время массового цветения гибридов отмечена в пре- делах 40-64 см (в среднем 48,4 $\pm 2,5, \mathrm{~V}=15,5 \%$ ), что важно для создания ландшафтных композиций для озеленения городских и приусадебных участков. Цветоносы у гибридов в среднем на 12,5 см возвышаются над листьями, а у контрольного сорта Golden Goft - на 10,0 см. Лучшее сочетание высоты цветоноса и куста из листьев у гибрида 20-07-17, листва в период массового цветения не закрывает цветки, так как не раскидистые, прочные цветоносы возвышаются над ними на 30 см. У остальных гибридов разница минимальная - 7-16 см. По оценке декоративности гибриды набрали от 69 до 98 баллов, контрольный сорт Golden Goft - 78 баллов. К набравшим 80 баллов и выше отнесены 5 гибридов.

Сопоставляя результаты оценки устойчивости, оригинальности и продуктивности, выделены следующие элитные гибриды:

1-06-15 (Cerry Queen×Tёркин) - красной окраски с чёрно-бархатистым отливом, на верхних лепестках красные прожилки, зев жёлтый, края гофрированные. Форма цветка треугольная, диаметр 14,3 см. Высота цветоноса 74 см, куста - 64 см. Высокопродуктивный (10 соцветий, 270 цветков на куст). Раннецветущий.

Морфологическая характеристика гибридов лилейника

Таблица 2

\begin{tabular}{|c|c|c|c|c|c|c|c|}
\hline \multirow[b]{2}{*}{ Сорт } & \multirow[b]{2}{*}{ Окраска } & \multicolumn{2}{|c|}{ Куст, См } & \multicolumn{2}{|c|}{ Цветок } & \multirow[b]{2}{*}{$\begin{array}{c}\text { Высота } \\
\text { цветоноса, } \\
\text { см }\end{array}$} & \multirow[b]{2}{*}{$\begin{array}{c}\text { Декора- } \\
\text { тивность, } \\
\text { балл }\end{array}$} \\
\hline & & $\begin{array}{c}\text { высо- } \\
\text { та }\end{array}$ & $\begin{array}{l}\text { диа- } \\
\text { метр }\end{array}$ & $\begin{array}{c}\text { диа- } \\
\text { метр, см }\end{array}$ & $\begin{array}{c}\text { оригиналь- } \\
\text { ность, } \\
\text { балл }\end{array}$ & & \\
\hline $\begin{array}{l}\text { Контроль } \\
\text { Golden Goft }\end{array}$ & Золотисто-жёлтая & $63 \pm 7,3$ & $69 \pm 1,6$ & $10,2 \pm 0,1$ & 4 & $73 \pm 3,9$ & 78 \\
\hline \multicolumn{8}{|c|}{ Миниатюрные (менее 7,8 см) } \\
\hline $22-07-4$ & Лимонно-жёлтая & $40 \pm 1,4$ & $45 \pm 1,4$ & $7,4 \pm 0,1$ & 4 & $56 \pm 3,5$ & 69 \\
\hline \multicolumn{8}{|c|}{ Крупноцветковые (11,4-17,5 см) } \\
\hline $1-06-15$ & Красная & $64 \pm 2,3$ & $60 \pm 2,6$ & $14,3 \pm 0,2$ & 5 & $74 \pm 2,1$ & 98 \\
\hline $3-07-3$ & Розовая & $53 \pm 1,7$ & $47 \pm 1,4$ & $15,2 \pm 0,3$ & 5 & $62 \pm 2,4$ & 78 \\
\hline $4-07-150$ & Малиново-красная & $49 \pm 2,3$ & $58 \pm 5,4$ & $12,3 \pm 0,2$ & 5 & $55 \pm 4,7$ & 91 \\
\hline $7-07-5$ & Ярко-красная & $46 \pm 1,7$ & $49 \pm 3,3$ & $14,2 \pm 0,2$ & 4 & $56 \pm 3,1$ & 80 \\
\hline $20-07-17$ & Красная & $45 \pm 1,7$ & $51 \pm 2,1$ & $16,2 \pm 0,2$ & 5 & $75 \pm 3,2$ & 98 \\
\hline $8-08-9$ & Темно-малиновая & $40 \pm 1,2$ & $37 \pm 1,4$ & $13,9 \pm 0,1$ & 5 & $51 \pm 1,0$ & 72 \\
\hline $19-08-2$ & Малиновая & $46 \pm 1,9$ & $62 \pm 4,0$ & $15,1 \pm 0,2$ & 5 & $57 \pm 4,0$ & 95 \\
\hline $19-08-3$ & Розовая & $53 \pm 1,3$ & $61 \pm 3,8$ & $14,7 \pm 0,2$ & 4 & $60 \pm 2,9$ & 71 \\
\hline Min-Max & & $40-64$ & $37-62$ & $7,4-16,2$ & & $51-75$ & $69-98$ \\
\hline$X \pm x$ & & $48,4 \pm 2,5$ & $52,2 \pm 2,9$ & $13,7 \pm 0,9$ & & $60,9 \pm 2,8$ & \\
\hline $\mathrm{V}, \%$ & & 15,5 & 16,5 & 19,0 & & 13,6 & \\
\hline
\end{tabular}


4-07-150 (Ugound×Cerry Queen) - малиновокрасной окраски и треугольной формы цветка, диаметр 12,3 см. Высота цветоноса 55 см, куста 49 см. Цветки слегка возвышаются над листьями. Продуктивность - 8 соцветий, 151 цветок на куст. Средний срок цветения.

7-07-5 (UffixRegal Air) - ярко-красной окраски c малиновым налётом с белой полоской на верхних лепестках, зев тыквенный. Цветок треугольной формы диаметром 14,2 см, ароматный. Высота куста 46 см, цветоноса - 56 см. Продуктивность - 6 соцветий, 66 цветков на куст. Средний срок цветения.

20-07-17 (рыже-каричневыйхRegal Air) - красной окраски, зев жёлтый, края гофрированные. Цветок паукообразной формы диаметром 16,2 cм, ароматный. Высота куста 45 см, цветоноса 75 см. Продуктивность - 9 соцветий, 195 цветков на куст. Средний срок цветения.

19-08-2 (Uffy×4-97-1) - малиновой окраски с белой полоской на верхних лепестках, зев жёлтый, края гофрированные. Цветок треугольной формы диаметром 15,1 см, ароматный. Высота куста 46 см, цветоноса - 57 см. Продуктивность - 6 соцветий, 121 цветок на куст. Позднецветущий.

\section{Заключение}

В условиях лесостепи Алтайского края изучены обильно цветущие гибриды лилейника Hemerocallis L. алтайской селекции с разными сроками цветения, продолжительностью декоративности более 2,5 мес. К лучшим отнесено 5 гибридов красной и малиновой окраски, треугольной и 1 паукообразной формы цветка, из них 2 высокорослых и 3 среднерослых.

\section{Библиографический список}

1. Зайцев, Г. Н. Математика в экспериментальной ботанике / Г. Н. Зайцев. - Москва: Наука, 1990. - 268 с. - Текст: непосредственный.

2. Макарычев, С. В. Гидротермический режим чернозёма под цветочными культурами в условиях Алтайского Приобья: монографрия /
С. В. Макарычев, И. А. Бицошвили. - Барнаул: РИО АГАУ, 2013. - 104 с. - Текст: непосредственный.

3. Методика государственного сортоиспытания сельскохозяйственных культур. Декоративные растения. - Москва: Колос, 1968. - 223 с. Текст: непосредственный.

4. Munson R.W. Jr. (1989). Hemerocallis, the daylily. Timber Press, Portland, Oregon. 144 p.

5. Русинова, Т. С. Лилейники - красоднев / Т. С. Русинова. - Текст: непосредственный // Новинки для сада и огорода. - Москва, 2001. № 3 - С. 5-6.

6. Селивёрстова, Е. Н. Виды и сорта лилейника гибридного в Ставропольском ботаническом саду / Е. Н. Селивёрстова. - Текст: непосредственный // Вестник АПК Ставрополья. 2016. - № 2 (22). - C. 246-248. - ISSN 2222-9345.

7. Спиридонова М. Нечаянная радость / М. Спиридонова. - Текст: непосредственный // Вестник цветовода. - 2008. - № 15 - С. 4-5.

\section{References}

1. Zaitsev G.N. Matematika v eksperimentalnoi botanike. - Moskva: Nauka, 1990. - $268 \mathrm{~s}$.

2. Makarychev S.V., Bitsoshvili I.A. Gidrotermicheskii rezhim chernozema pod tsvetochnymi kulturami v usloviiakh Altaiskogo Priobia: monografiia. - Barnaul: RIO AGAU, 2013. - 104 s.

3. Metodika gosudarstvennogo sortoispytaniia selskokhoziaistvennykh kultur // Dekorativnye rasteniia. - Moskva: Kolos. 1968. - 223 s.

4. Munson R.W. Jr. (1989). Hemerocallis, the daylily. Timber Press, Portland, Oregon. 144 p.

5. Rusinova T.S. Lileiniki - krasodnev // Novinki dlia sada i ogoroda. - 2001. - No. 3. - S. 5-6.

6. Seliverstova E.N. Vidy i sorta lileinika gibridnogo v Stavropolskom botanicheskom sadu // Vestnik APK Stavropolia. - 2016. - No. 2 (22). S. 246-248.

7. Spiridonova M. Nechaiannaia radost // Vestnik tsvetovoda. -2008 . - No. 15 - S. 4-5. 